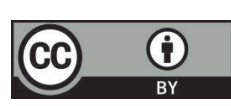

\title{
Clinical presentation of COVID-19 and public health implications to Sri Lanka
}

Bhumini Karunarathna', Chithramali Rodrigo', Dharshini Kantharuban², Indumini Gunatilake ${ }^{3}$, Maheeka Seneviwickrama ${ }^{4}$, Sampatha Goonewardena ${ }^{4}$, Pushpa Jayawardana ${ }^{5}$ Ishanka Ayeshwari Talagala ${ }^{1^{*}}$

${ }^{1}$ Ministry of Health, Sri Lanka; ${ }^{2}$ Provincial Director of Health Services office- Eastern Province, Trincomalee, Sri Lanka; ${ }^{3}$ Postgraduate Institute of Medicine, University of Colombo, Sri Lanka; ${ }^{4}$ Department of Community Medicine, Faculty of Medical Sciences, University of Jayewardenepura, Sri Lanka; ${ }^{5}$ No affiliation

"Correspondence: drishanka@gmail.com iDhttps://orcid.org/0000-0001-6351-2079

DOI: https://doi.org/10.4038/jccpsl.v26i5.8342

Received on 17 May 2020

Accepted on 25 May 2020

\section{Highlights}

- Fever, cough and shortness of breath are the commonest presenting symptoms of COVID-19, while the atypical findings include gastro-intestinal, olfactory and gustatory symptoms.

- COVID-19 can be spread by asymptomatic patients, where the communicable period among them could be as high as 29 days.

- Older patients with comorbidities are more prone for severe coronavirus disease which would result in pneumonia, acute respiratory distress syndrome and arrhythmia, requiring ICU care.

\section{Background}

Coronavirus disease 2019 (COVID 19) is caused by a novel coronavirus named SARS-CoV-2. The first coronavirus to emerge following a spill over from animals to humans during this century was SARS coronavirus (SARS-CoV) in November 2002, resulting in Severe Acute Respiratory Syndrome (SARS). The second, Middle East Respiratory Syndrome (MERS) caused by a coronavirus (MERS$\mathrm{CoV})$, resulted in the MERS-Co-V outbreak in 2012 (1). SARS-CoV-2 is the third coronavirus that emerged in China in 2019 resulting in the coronavirus disease and the World Health Organization (WHO) declared it a pandemic on 11 March 2020. As of 2 May 2020, there were 2,126,649 suffering from COVID-19, with 244,481 deaths across the globe (2). In Sri Lanka, there were 690 COVID-19 infected cases and seven deaths by 2 May 2020 (3).

\section{Common clinical features of COVID-19}

COVID-19 is a disease with a wide range of signs and symptoms that can appear within 2-14 days of exposure to the virus (4). Fever, cough and shortness of breath are reported to be the commonest symptoms of the infection (4-5). However, according to the WHO, fever, tiredness and dry cough have been the 
commonest clinical presentations, while some patients may even have body aches and pains, nasal congestion, runny nose, sore throat, diarrhoea (6), loss of appetite (7), headache, dizziness, abdominal pain, nausea and vomiting (8). However, symptoms like runny nose and sputum were found to be rare among the Chinese patients with COVID-19 (9). Furthermore, a study conducted on the clinical characteristics of COVID-19 $(n=138)$ found that all of the infected patients had abnormal chest CT reports, including bilateral patchy shadows or ground glass opacity in the lungs (8).
A systematic review on the clinical characteristics of COVID-19 found that the commonest symptoms of coronavirus disease among hospital patients in China were fever $(91.3 \%$; 95\% confidence interval $(\mathrm{CI})=86 \%, 97 \%)$. cough $(67.7 \% ; 95 \% \mathrm{CI}=59 \%$, $76 \%)$; fatigue $(51 \% ; 95 \% \mathrm{CI}=4 \%, 68 \%)$ and dyspnoea $(30.4 \% ; 95 \% \mathrm{CI}=21 \%, 40 \%)$. However, these clinical features showed a significant $(\mathrm{p}<0.001)$ heterogeneity with $\mathrm{I}^{2}$ (a statistic that indicates the percentage of variance in a meta-analysis that is attributable to study heterogeneity) varying from $84.9 \%$ - 96.4\% (10). Comparison of clinical presentations of recent respiratory viruses is shown in Table 1.

Table 1. Clinical presentations of recent respiratory viral infections

\begin{tabular}{|c|c|c|c|}
\hline Infection & $\begin{array}{l}\text { Common signs and } \\
\text { symptoms }\end{array}$ & Complications & Burden of the disease \\
\hline Influenza & $\begin{array}{l}\text { Abrupt onset of constitutional } \\
\text { and upper respiratory tract signs } \\
\text { and symptoms such as fever, } \\
\text { chills, myalgia, headache, } \\
\text { malaise, non-productive cough, } \\
\text { sore throat and rhinitis (11) }\end{array}$ & $\begin{array}{l}\text { Otitis media, bronchiolitis, } \\
\text { tracheitis, myocarditis, } \\
\text { pericarditis, severe myositis } \\
\text { (11 }\end{array}$ & $\begin{array}{l}\text { Highest global death rate } \\
\text { among all ages was } 5.2 \text { per } \\
100,000 \text { population }(95 \% \\
\mathrm{CI}=3 \cdot 5,7 \cdot 2) \text {. Estimated } \\
\text { hospitalizations due to } \\
\text { lower respiratory tract } \\
\text { infections are } 9,459,000 \\
(95 \% \mathrm{CI}=3,709000, \\
22,935,000) \text { and } 81,536,000 \\
\text { hospital days }(24,330,000, \\
259,851,000) \text { across the } \\
\text { world }(12)\end{array}$ \\
\hline $\begin{array}{l}\text { Severe Acute } \\
\text { Respiratory } \\
\text { Syndrome } \\
\text { (SARS) ( } 2003 \\
\text { outbreak) }\end{array}$ & $\begin{array}{l}\text { Fever, malaise, myalgia, } \\
\text { headache and rigor during first } \\
\text { week; cough (initially dry), } \\
\text { dyspnoea and diarrhoea during } \\
\text { the second week (13) }\end{array}$ & $\begin{array}{l}\text { Pneumonia, cardiac failure, } \\
\text { liver failure (14) }\end{array}$ & $\begin{array}{l}8098 \text { infected, } 774 \text { deaths } \\
\text { worldwide (15) }\end{array}$ \\
\hline $\begin{array}{l}\text { Middle East } \\
\text { Respiratory } \\
\text { Syndrome } \\
\text { (MERS) }\end{array}$ & $\begin{array}{l}\text { Fever, cough and shortness of } \\
\text { breath, pneumonia, diarrhoea } \\
\text { (16) }\end{array}$ & Respiratory failure (16) & $\begin{array}{l}2494 \text { infected and } 858 \\
\text { deaths worldwide } \\
(\mathrm{CFR}=34.4 \%) \text { from } \\
\text { September } 2012 \text { to } \\
\text { November } 2019 \text { (17) }\end{array}$ \\
\hline $\begin{array}{l}\text { Coronavirus } \\
\text { disease } 2019 \\
\text { (COVID-19) }\end{array}$ & $\begin{array}{l}\text { Fever, dry cough, fatigue, } \\
\text { shortness of breath (6) }\end{array}$ & $\begin{array}{l}\text { Acute Respiratory Distress } \\
\text { Syndrome (ARDS), } \\
\text { pneumonia, cardiovascular } \\
\text { complications, acute liver } \\
\text { injury, cytokine-release } \\
\text { syndrome (18) }\end{array}$ & $\begin{array}{l}\text { As of } 2 \text { May } 2020 \text {, there } \\
\text { were } 2,126,649 \text { infected } \\
\text { with } 244,481 \text { deaths } \\
\text { worldwide (2) }\end{array}$ \\
\hline
\end{tabular}


However, it is believed that most infected people with COVID-19 may not develop any symptoms or will experience only a mild to moderate respiratory illness, while around $80 \%$ would recover without requiring any special treatment. It is estimated that only 1 in every 5 people who are infected with coronavirus would become seriously ill and develop difficulty in breathing (6).

\section{Atypical clinical features of COVID-19}

A multi-centre European study among 417 COVID19 patients has reported that apart from the common respiratory symptoms, olfactory and gustatory disorders were found to be prevalent (19). Around $86 \%$ of these patients had complaints on olfactory dysfunction including anosmia (79.6\%) and hyposmia $(20.4 \%)$. The mean time from the onset of disease to the assessment among these patients was $9.77(\mathrm{SD}=5.68)$ days. However, most of these olfactory dysfunctions had recovered within eight days of resolution of the coronavirus disease. On the other hand, $88.8 \%$ of the patients had complaints on gustatory disorders characterized by taste impairments for salt, sweet, bitter and sour tastes. Among these patients, $78.9 \%$ had reduced ability to taste flavours, while for $21.1 \%$ this ability was distorted (7).

Another multi-centre study conducted among 204 COVID-19 confirmed patients in Hubei, China, has shown that $18.6 \% \quad(n=38)$ presented with gastrointestinal symptoms such as diarrhoea, vomiting and abdominal pain (7). It is important to note that patients with digestive symptoms were significantly delayed in their hospital admission from the onset of symptoms compared to those without any digestive symptoms ( 9 days versus 7.3 days; $p=0.02$ ). It is also reported that, as the severity of coronavirus disease increases, the digestive symptoms become more prominent, although the discharge time and duration requiring ICU care or mortality were not significantly different from those who did not have any digestive symptoms (7).

Also, it was shown that patients with digestive symptoms had significantly higher levels of liver enzymes $(p=0.002$ for ALT; $p=0.008$ for AST) suggestive of liver injury; and had longer prothrombin time (13.1 versus 12.5 seconds) compared to those without digestive symptoms (7-8).

\section{Asymptomatic COVID-19}

The mean incubation period of the coronavirus infection is estimated to be 6.4 days $(95 \% \mathrm{CI}=5.6$, $7.7)$, with a range of 2.1 to 11.1 days $\left(2.5^{\text {th }}\right.$ and $97.5^{\text {th }}$ centile) (20). Therefore, an infected individual with coronavirus would either be symptomatic, asymptomatic or show no symptoms at all during and after this period. The coronavirus infection is transmitted predominantly by symptomatic individuals (symptomatic transmission). It has been shown that an infected person may shed the coronavirus for 24-48 hours prior to the onset of symptoms. This would allow the spread of the infection via apparently healthy individuals before the onset of symptoms (pre-symptomatic transmission) (6). Also, it is evident that the disease could be transmitted through asymptomatic individuals (asymptomatic transmission) and/or from convalescents (21-23). Asymptomatic transmission of the coronavirus infection has made primary prevention of the disease spread quite challenging.

An asymptomatic laboratory-confirmed case is defined as "a person infected with COVID-19 who does not develop symptoms" (24). Despite the understanding that the transmission potential of asymptomatic coronavirus cases is low, there is evidence to suggest otherwise.

A study from Anyang, China reported of a family of five members becoming symptomatic of COVID-19 following contact with an asymptomatic family member who had returned from Wuhan, China (21). This returnee was recognized as an asymptomatic laboratory-confirmed case with a positive reverse transcriptase polymerase chain reaction (RT-PCR) after 19 days of her return from Wuhan. She developed no symptoms throughout the one-month period of isolation while other laboratory tests and CT imaging had remained normal despite the positive RT-PCR (21). Another study from Nanjin, China, reported a similar familial cluster of three 
symptomatic patients following contact with an asymptomatic laboratory-confirmed COVID-19 case returning from Hubei, China. The asymptomatic contact had tested positive for RT-PCR 29 days after returning from Hubei, suggesting a longer communicable period among asymptomatic individuals. Further, it was found that the median communicable period, which is defined as the period from the first test positive day to the first day of consecutive negative tests was 9.5 days [interquartile range (IQR): 3.5-13 days] among the 24 asymptomatic cases in this study (23).

The proportion of asymptomatic infected individuals among the total number of infected (asymptomatic proportion) is a useful measure of the true burden of the disease, which helps to understand the transmission potential of the disease. A study conducted to determine the case load of COVID-19 infection on board the Diamond Princess cruise ship, Yokohama, Japan, reported that on 20 February 2020 which was the $14^{\text {th }}$ day of quarantine, the proportion of asymptomatic individuals has been as high as $50.5 \%$ (320 out of total number of 634 cases). Further, there has been no significant difference in viral titres between symptomatic and asymptomatic patients on board the ship (25).

It has been observed that asymptomatic laboratoryconfirmed cases of COVID-19 tend to be younger compared to those who develop symptoms (median age $=14.0$ years; $p=0.012$ ) (23). It is suggested that repeated testing would be crucial to identify asymptomatic infections among young close contacts, especially when resuming work and schooling following the current lockdown situation. However, large-scale multicentre studies are needed to further evaluate the dynamics of asymptomatic COVID-19 transmission.

Considering the Sri Lankan situation, according to the chief consultant physician at the National Institute of Infectious Diseases (NIID), it is estimated that around $2 / 3^{\text {rd }}$ of the RT-PCR test positive cases in Sri Lanka are asymptomatic. The large number of testing done in proportion to the population could be the best explanation for this large asymptomatic cohort (26).

\section{Critical cases of COVID-19}

The emergency warning signs for COVID-19 to get immediate medical attention include difficulty in breathing, persistent pain or pressure in the chest, confusion that is of new onset or inability to wake up or be woken up and bluish lips or face (4). However, it is important to note that this list is not all inclusive. It is reported that in severe cases, the coronavirus disease can progress rapidly resulting in pneumonia, ARDS, septic shock, irreversible metabolic acidosis and coagulation disorders in just a matter of days (8). A systematic review among 5,732 COVID-19 patients reported that the proportion of severe cases was $24.3 \%$; incidence of ARDS was $14.8 \%$ and the mortality rate was $6.4 \%(5)$.

A single centre retrospective case-series of 138 hospitalized patients diagnosed with COVID-19 in Wuhan, China, stated that $26.1 \%$ of the cases required intensive care unit (ICU) management following ARDS (61.1\%), arrhythmia (44.4\%) and shock (30.6\%) (27). Of these patients, $11.1 \%$ required high-flow oxygen therapy, $41.7 \%$ were given non-invasive ventilation and $47.2 \%$ required invasive ventilation. It is reported that the median time duration from the day of onset of the first symptom to the onset of dyspnoea was 5.0 (IQR:110) days; to hospital admission was 7.0 (IQR:4-8) days; and to ARDS was 8.0 (IQR:6-12) days. Authors claimed that majority of the patients in the ICU with complicated disease of COVID-19 were older (median age 66 (IQR:57-78) years versus. 51 (IQR:37-62) years; p<0.001); suffering with comorbidities such as hypertension (58.3\%), diabetes $(22.2 \%)$, cardiovascular disease $(25 \%)$ and cerebrovascular disease $(16.7 \%)$; were dyspnoeic $(63.9 \%)$ and were anorexic $(66.7 \%)(8)$. It is found that severe cases may even result in acute cardiac injury leading to death (27).

According to the chief consultant physician at NIID, as of 30 April 2020, there had been 16 critical COVID-19 cases in Sri Lanka and seven out of them had died. Out of the seven deaths, one patient had died at the time of admission, while another, a few hours later. Other five deaths had occurred despite providing ICU care (26). However, the case fatality 
rate of COVID-19 (2.3\%) was found to be lower than that of SARS (9.6\%) and MERS (35\%) (5, 15-16).

\section{Public health implications of the knowledge on typical and atypical clinical presentation}

Awareness of the clinical features, both typical and atypical, of COVID-19 is important in many aspects. Since this is a disease caused by a novel virus, knowing the clinical features would support in better understanding of the patterns of patient presentation and how the disease behaves. COVID-19 was initially identified only as a cluster of atypical pneumonia cases in Wuhan, China in December 2019. The reporting of clinical features resulted in the development of case definitions, such as 'confirmed', 'probable' and 'suspected' cases, leading to easy identification of them.

Establishing a case definition and knowledge on the clinical features of the disease is essential for: a) primary prevention of the disease, whereby identifying a case early, adequate measures (social isolation, respiratory etiquette, hand washing) can be undertaken to prevent the spread of the disease and would also support in educating the community to prevent themselves from being exposed to a case. Recent Chinese studies have revealed that majority of the people had good knowledge regarding COVID19 including the knowledge of common symptoms and signs, which had helped to sustain the optimistic attitudes and appropriate practices of people towards COVID-19 (28); b) Secondary prevention of the disease, where knowledge of the clinical features among the population would improve the healthcare seeking behaviour leading to early identification and early initiation of treatment. The knowledge of clinical features among the healthcare staff would improve early identification and initiation of treatment for the disease. Furthermore, it would also support in monitoring patients, understanding the impact of on-going treatment and in preventing complications; c) Tertiary prevention of the disease by anticipating the known complications in those with severe form of the disease would support early identification and treatment and thereby prevent negative outcomes of the disease. Furthermore, a study conducted in China has stated that the majority of the healthcare workers were aware of common symptoms and had good attitudes towards COVID19, which might have supported massively in the management of this disease (29); and d) Surveillance purposes, to quantify the magnitude and to find out the disease distribution in a given population, in a given geographical area and e) research purposes.

\section{Gaps in the existing knowledge}

While commending Sri Lanka for the exceptional efforts that have been implemented to prevent the transmission of COVID-19, it is important to note that detailed local knowledge on typical and atypical signs and symptoms of COVID-19 and severe disease is lacking. Also, the proportion of patients with comorbidities and their risk of getting complicated disease for Sri Lankan patients with COVID 19 are not available.

\section{Applicability of the evidence on typical and atypical clinical features of COVID-19 to Sri Lanka}

In the absence of published data related to typical and atypical clinical presentations and severe forms of COVID-19 in Sri Lanka, the ongoing response process for treatment and management of coronavirus disease in the country is largely dependent on findings from other countries. However, it is essential to inquire on the applicability of these findings to Sri Lanka, for example, it is important to understand whether the signs and symptoms of COVID-19 are similar in a tropical country like Sri Lanka as well. Thus, it is critical to record the findings from Sri Lanka for better management of patients within our resource-limited health system.

\section{Recommendations for COVID 19 response in Sri Lanka}

With this background, reporting of typical, atypical symptoms and signs of COVID-19 among Sri Lankan patients is recommended. Since the disease spread can happen via asymptomatic positive cases of COVID-19, it is essential to maintain social 
distancing with each other, even after the current curfew system is lifted. This is of utmost importance to those who are old and suffering from other comorbidities, considering their susceptibility for infection and severe disease. Since the disease spread is found to be common from convalescents, selfquarantine and repeat testing of COVID-19 patients is recommended even after being discharged. Repeated testing would be crucial to identify asymptomatic infections among young close contacts, especially when resuming work and schooling following the current lockdown situation.

\section{Author Declaration}

Author contributions: BK, CR and IAT have made substantial contributions to the conception, drafting and critical analysis for the intellectual content of the manuscript. All authors agreed to be accountable for all aspects of the work in ensuring that questions related to the accuracy or integrity of any part of the work are appropriately investigated and resolved. All authors have read and approved the manuscript.

\section{References}

1. National Institute of Allergy and Respiratory Diseases. Coronaviruses. 2020. Available from:https://www.niaid.nih.gov/diseasesconditions/coronaviruses .Accessed 30 April 2020.

2. Worldometer. COVID-19 Coronavirus Pandemic. Available from: https://www. world ometers. info/coronavirus. Accessed 2 May 2020.

3. Epidemiology Unit, Sri Lanka. Coronavirus disease 2019 (COVID-19) - Situation Report - 02.05.2020. Available from: http://www.epid .gov.lk/web/ images/pdf/corona_virus_report/sitrep-sl-en-0205_10.pdf. Accessed 2 May 2020.

4. Centre for Disease prevention and Control (CDC). Symptoms of Coronavirus 2020. Available from: https://www.cdc.gov /coronavirus/2019-ncov/ about/symptoms. html. Accessed 28 April 2020.

5. Sun P, Qie S, Liu Z, Ren J, Xi J. Clinical characteristics of 5732 patients with 2019-nCoV infection. Available from: https://papers. ssrn.com/sol3/papers.cfm?abstract_id=3539664.

6. World Health Organization. $Q \& A$ on coronaviruses (COVID-19) 2020. Available from: https:// www.who.int/news-room/q-a-detail/q-a-corona viruses. Accessed 27 April 2020.

7. Pan L, Mu M, Yang P, Sun Y, Wang R, Yan J, Li P, $\mathrm{Hu} \mathrm{B}$, Wang J, Hu C, \& Jin Y. Clinical characteristics of COVID-19 patients with digestive symptoms in Hubei, China: a descriptive, crosssectional, multicentre study. The American Journal of Gastroenterology 2020: 115: 766-773. DOI: 10.14309/ajg. 0000000000000620.

8. Wang D, Hu B, Hu C, Zhu F, Liu X, Zhang J, Wang B, Xiang H, Cheng Z, Xiong Y, Zhao Y. Clinical characteristics of 138 hospitalized patients with 2019 novel coronavirus-infected pneumonia in Wuhan, China. JAMA 2020; 17; 323 (11): 10611069. DOI: $10.1001 /$ jama.2020.1585.

9. Huang C, Wang Y, Li X, Ren L, Zhao J, Hu Y, Zhang L, Fan G, Xu J, Gu X, Cheng Z. Clinical features of patients infected with 2019 novel coronavirus in Wuhan, China. The Lancet. 2020; 395(10223): 497-506. DOI: 10.1016/S01406736(20)30183-5.

10. Yang J, Zheng Y, Gou X, Pu K, Chen Z, Guo Q, Ji R, Wang H, Wang Y, Zhou Y. Prevalence of comorbidities in the novel Wuhan coronavirus (COVID-19) infection: a systematic review and meta-analysis. International Journal of Infectious Diseases 2020; 94: 91-95. DOI: 10.1016/ j.ijid.2020.03.017.

11. Centres for Disease Control and Prevention \& National Centre for Immunization and Respiratory Diseases (NCIRD). Clinical signs and symptoms of Influenza, 2019. Available from: https://www.cdc. gov/flu/professionals /acip/clinical.htm Accessed 29 April 2020.

12. Troeger, C.E., Blacker, B.F., Khalil, I.A., Zimsen, S.R., Albertson, S.B., Abate, D., Abdela, J., Adhikari, T.B., Aghayan, S.A., Agrawal, S., \& Ahmadi, A. Mortality, morbidity, and hospitalisations due to influenza lower respiratory tract infections, 2017: an analysis for the Global Burden of Disease Study 2017. The Lancet Respiratory Medicine 2019 7(1): 69-89. DOI: 10.1016/S2213-2600 (18)30496-X.

13. World Health Organization. WHO guidelines for the global surveillance of severe acute respiratory syndrome. 2004. Available from: https:// www.who.int/csr/resources/publications/WHO_C DS_CSR_ARO_2004_1.pdf._Accessed 29 April 2020. 
14. Mayo Clinic. Severe Acute Respiratory Syndrome (SARS) 2019. Available from:https:// www. mayoc linic.org/diseases-conditions/sars/ symptomscauses/syc-20351765. Accessed 28 April 2020.

15. Centres for Disease prevention and Control (CDC). Severe Acute Respiratory Syndrome (SARS) 2004. Available from: https://www.cdc. gov/sars/about/fsSARS.pdf. Accessed 28 April 2020.

16. World Health Organization. Middle East respiratory syndrome coronavirus (MERS-CoV) 2019. Available from: https://www.who. int/news$\mathrm{room} /$ fact-sheets/detail/middle-east-respiratorysyndrome-coronavirus-(mers-cov). Accessed 29 April 2020.

17. World Health Organization (WHO). Middle East Respiratory Syndrome coronavirus (MERS-CoV) 2020. Available from: https:// www.who.int/ emergencies/mers-cov/en/. Accessed 27 April 2020.

18. BMJ Publishing group. Corona Virus Disease 2019 (COVID-19). 2020. Available from: https:// bestpractice.bmj.com/topics/en-us/3000168/ complications. Accessed 1 May 2020.

19. Lechien JR, Chiesa-Estomba CM, De Siati DR, Horoi M, Le Bon SD, Rodriguez A, Dequanter D, Blecic S, El Afia F, Distinguin L, Chekkoury-Idrissi Y. Olfactory and gustatory dysfunctions as a clinical presentation of mild-to-moderate forms of the coronavirus disease (COVID-19): A Multicentre European Study. European Archives of Oto-RhinoLaryngology 2020; 277: 2251-2261. DOI: 10.1007/s00405-020-05965-1.

20. Backer JA, Klinkenberg Don, Wallinga J. Incubation period of 2019 novel coronavirus (2019$\mathrm{nCoV}$ ) infections among travellers from Wuhan, China, 20-28 January 2020. Eurosurveillance 2020; 25(5): pii=2000062. DOI: $10.2807 / 1560$ 7917.ES.2020.25.5.2000062.

21. Bai Y, Yao L, Wei T, et al. Presumed asymptomatic carrier transmission of COVID- 19. JAMA 2020; 323(14): 1406-1407. DOI: 10.1001/jama. 2020.2565 .

22. Rothe C, Schunk M, Sothmann P, Bretzel G, Froeschl G, Wallrauch $\mathrm{C}$, et al. Transmission of 2019-nCoV infection from an asymptomatic contact in Germany. New England Journal of Medicine
2020; 382: 970-971. DOI: 10.1056/NEJMc 2001468.

23. Hu Z, Song C, Xu C, Jin G, Chen Y, Xu X, Ma H, Chen W, Lin Y, Zheng Y, Wang J. Clinical characteristics of 24 asymptomatic infections with COVID-19 screened among close contacts in Nanjing, China. Science China Life Sciences 2020; 63: 706-711. DOI: 10.1007/s11427-020-1661-4.

24. World Health Organization. Coronavirus disease 2019: Situation Report 73. 2020. Available from: https://www.who.int/docs/default-source/ corona viruse/situation-reports/20200402-sitrep-73-covid19.pdf.

25. Mizumoto K, Kagaya K, Zarebski A, Chowell G. Estimating the asymptomatic proportion of coronavirus disease 2019 (COVID-19) cases on board the Diamond Princess cruise ship, Yokohama, Japan, 2020. Eurosurveillance 2020; 25(10): pii=2000180. DOI: 10.2807/ 1560-7917. ES.2020.25.10.2000180

26. Hapuarachchi P. Sri Lanka's 2/3 of COVID-19 positive patients "asymptomatic". News First, 30 April 2020. Available from: https:// www. newsfirst.lk/2020/04/30/sri-lankas-2-3rd-of-covid19-positive-patients-asy mptomatic/. Accessed 1 May 2020.

27. Shi S, Qin M, Shen B, Cai Y, Liu T, Yang F, Gong W, Liu X, Liang J, Zhao Q, Huang H. Association of cardiac injury with mortality in hospitalized patients with COVID-19 in Wuhan, China. JAMA Cardiology 2020; 5(7): 802-810. DOI: 10.1001/jamacardio. 2020.0950.

28. Zhong BL, Luo W, Li HM, Zhang QQ, Liu XG, Li WT, Li Y. Knowledge, attitudes, and practices towards COVID-19 among Chinese residents during the rapid rise period of the COVID-19 outbreak: a quick online cross-sectional survey. International Journal of Biological Sciences 2020; 16(10): 1745. DOI: 10.7150/ijbs.45221.

29. Giao H, Han NTN, Van Khanh T, Ngan VK, Van Tam V, Le An P. Knowledge and attitude toward COVID-19 among healthcare workers at District 2 Hospital, Ho Chi Minh City. Asian Pacific Journal of Tropical Medicine 2020; 13(6): 260-265. DOI: 10.4103/1995-7645.280396. 